\title{
The Fundamental Articles of I.AM Cyborg Law
}

\author{
Stephen Castell \\ CASTELL Consulting, Witham, UK \\ Email: stephen@castellconsulting.com
}

How to cite this paper: Castell, S. (2020). The Fundamental Articles of I.AM Cyborg Law. Beijing Law Review, 11, 911-946. https://doi.org/10.4236/blr.2020.114055

Received: November 2, 2020

Accepted: December 15, 2020

Published: December 18, 2020

Copyright (c) 2020 by author(s) and Scientific Research Publishing Inc. This work is licensed under the Creative Commons Attribution International License (CC BY 4.0).

http://creativecommons.org/licenses/by/4.0/

\begin{abstract}
Author Isaac Asimov first fictionally proposed the "Three Laws of Robotics" in 1942. The word "cyborg" appeared in 1960, describing imagined beings with both artificial and biological parts. My own 1973 neologisms, "neural plug compatibility", and "softwiring" predicted the computer software-driven future evolution of man-machine neural interconnection and synthesis. Today, Human-AI Brain Interface cyborg experiments and "brain-hacking" devices are being trialed. The growth also of Artificial Intelligence (AI)-driven Data Analytics software and increasing instances of "Government by Algorithm" have revealed these advances as being largely unregulated, with insufficient legal frameworks. In a recent article, I noted that, with automation of legal processes and judicial decision-making being increasingly discussed, RoboJudge has all but already arrived; and I discerned also the cautionary Castell's Second Dictum: "You cannot construct an algorithm that will reliably decide whether or not any algorithm is ethical". With few established elements of law and jurisprudence available that readily map to the Machine Species, any new "Cyborg Law" has to be drafted on a tabula rasa basis. Cyborg Law furthermore needs to consider that by "Machine Species" could be meant one that is self-aware existentially, with a distinct legal personality, which I here christen the Intelligent Autonomous Machine ("I.AM") Species: sum ergo cogito. This paper develops Fundamental Articles of Cyborg Law ("FACLs") by way of setting-out putative legal text for a draft Cyborg Act 2021, constituting the first substantive attempt to develop a tangible Cyborg Law. This is work-in-progress, to which others are invited to contribute.
\end{abstract}

\section{Keywords}

Cyborg, Law, Artificial Intelligence, Algorithm, Ethics

\section{Introduction}

Author Isaac Asimov first fictionally proposed the "Three Laws of Robotics" in his 1942 short story "Runaround", in the 1950 collection "I, Robot". However, 
Asimov himself came to recognise these rules as inadequate for the imminent Intelligent Machine Age. The word "cyborg" itself appeared in 1960 when scientists Manfred Clynes and Nathan S. Kline used it to describe imagined beings with both artificial and biological parts. My own neologisms, "neural plug compatibility", and "softwiring", coined in 1973, envisioned and predicted the computer software-driven future evolution of man-machine neural interconnection and synthesis.

Beyond this, as far as I am aware, "Cyborg" is not a Term of Art, and there is as yet no settled definition, nor, for example, a relevant international standard. The definition given, for example, in https://www.linternaute.fr/dictionnaire/fr/definition/cyborg/ is again simply "Cyborg is a term that ... is a neologism which designates an android being half robot and half human". (As can be seen from

https://www.whois.com/whois/cyborg.com, the domain cyborg.com was registered in 1995, albeit there does not seem to be an active website.)

Today, Artificial Intelligence (AI)-Human-Brain Interface experiments and "brain-hacking" devices, exploring and demonstrating the potential of real cyborg products and systems are available, being trialed, and spreading. Other AI-fuelled entities such as avatars, robots, bots, and androids are flourishing, conceptually, imaginatively and practically, in entertainment and media, in digital cyberspace, and in physical production.

These range, just by way of one example, from the "Perfect Girlfriend Who Knows You Best”, whose vendors say (Robot Companion, undated) “Our Artificially Intelligent Robot Companions can discuss your day or please you for hours without complaint. The choice is always yours. Robot conversation or robot stimulation?", to "Miquela, the virtual pop star and digital influencer" who is "literally digital ... The avatar, music artist and social activist are the product of L.A.-based digital studio Brud. ... constantly the subject of the question, "Are you real?" ... Miquela has 5 million followers on social media... This past May, $C A A$ signed Miquela as the agency's first virtual client' (Spangler, 2020).

I myself invented the CastellGhostWriteBot whose most recent literary effort, "Authored by AI", was a column published in Solicitors Journal dealing with cryptocurrency and crypto asset disputes: "Are you crypto-friendly, or if not, at least crypto-aware?" (Castell, 2019)

Furthermore, the rapid growth of AI-driven Data Analytics software and the associated increasing instances of "Government by Algorithm" have revealed these advances as being largely unregulated, with potentially insufficient legal frameworks currently. In 2017 I called for and promoted the formation of an international Action Group for Robotic Integration and Control, AGRIC, and proposed to the UK government the appointment of a Senior Cabinet Minister for AI.

In another recent article (Castell, 2018), I observed that, with automation of legal processes and judicial decision-making themselves being increasingly dis- 
cussed, and trialled, the AI Age is truly upon us: RoboJudge has all but already arrived. It should however be noted that, in that much-cited article, I developed the cautionary expert insight that, while many are concerned about defining and developing regulatory principles based on the idea, or hope, of "Algorithmic Fairness", and/or are preoccupied with the wider concept of "Machine Ethics", Castell s Second Dictum: "You cannot construct an algorithm that will reliably decide whether or not any algorithm is ethical" reveals that all such aspiration or objective is essentially a futile exercise.

It is abundantly clear, then, that few, if any, established concepts, principles and practices of law and jurisprudence readily map from human societal ordering, endeavours and situations to the Machine Species. Any new "Cyborg Law" therefore has to be drafted on a tabula rasa basis. Such a drafting exercise needs to appreciate that by "Machine Species" could readily be meant one that is arguably self-aware existentially, with potentially a standalone "legally-recognized existence", which I here christen the Intelligent Autonomous Machine ("I.AM") Species: sum ergo cogito.

The scope of the I.AM Cyborg Law is therefore undoubtedly wide, raising many intense and challenging issues. Will Cyborg Law necessarily require there to continue to be, individually and/or organisationally, human Trusted Third Parties ultimately responsible and liable for a cyborg's actions, and the consequences thereof? Or, rather, will Cyborg Law encompass the definition, and principles of responsibility and accountability, of a distinct human-independent cyborg legal personality?

A further example of the profundity of this exercise is that Cyborg Law may need to encompass the concept of a cyborg's body being physically present, but the cyborg's brain being wholly or partly "in the Datacloud". There could thus potentially be much actual, and evolving, "Datacloud Law", to be taken into account, and the intriguing possibility of a "Body-Cloud" existence would additionally open up a whole new dimension of hitherto unaddressed legal considerations and issues.

What is clear is that there is no precedent, legal guidance, regulatory strictures, or other conventions, to constrain the answer to the question "Who gets to draft Cyborg Law?" and this paper seizes the initiative to take a first step in developing and issuing the elements of a First Draft Cyborg Law. The paper begins by setting out the author's review, analysis and propositions as to some applicable considerations, by way of:

- Review of literature.

- Principles and practices of drafting Cyborg Law.

- Scientific interface.

- Principal Requirements of Cyborg Law.

This paper then goes on to fashion the author's draft for the Fundamental Articles of Cyborg Law ("FACLs") by way of setting-out putative legal text for a Cyborg Act 2021. This is work-in-progress, to which others are warmly invited, 
via contact and correspondence with the author, to contribute. Examples of previous related background work and theories are provided, as listed at [4] [6] and [7] in Background Reading hereof. However, the author has not been able to discover any prior work specifically focused on the FACL propositions and principles of the draft Cyborg Act 2021 as herein developed.

This paper constitutes, as far as is known, the first substantive attempt anywhere to develop draft text of a tangible Cyborg Law, and, with further development, hopefully one set on a path that is potentially capable of becoming legally sound, and creating a foundation for actual future parliamentary legislation, or other forms of statutory legislative development.

\section{The Scope and Application Domain of Cyborg Law}

\section{Review of Literature}

Within Cyborg Law literature that I have reviewed there is an emphasis on "digital rights" as they might apply to cyborgs, on the one hand, and on the issue of "harm to humans" on the other. The overarching and driving perception some express it as a fear, is that the I.AM Species will at some point, perhaps quite soon, become more intelligent than humans, and in ways we may not even be able to comprehend, much less control.

Zoltan Istvan, Transhumanist, in his posting "Do cyborgs need their own legal rights?" (Istvan, 2019), asks “When the machines we ve created possess an intelligence that equals ours, will they deserve our protection? Will they desire it? Maybe even demand it?".

Stephen Fleischfresser, referring also to the work of Robin R Murphy of Texas A\&M University in the US, in a posting "Legal problems loom for cyborgs" (Fleischfresser, 2019), emphasises "the gap between the law and our capacity to augment our bodies and minds", and notes that "works of science fiction ... have done much to anticipate the technological developments and trends of our slow transformation into cyborgs. However ... they have done little to predict many of the ethical and legal complications that will accompany them".

"Who controls the tech inside us?" asks Dyllan Furness, noting the experience of Karen Sandler (now the executive director of Software Freedom Conservancy) with her heart pacemaker implant (Furness, 2018): "Sandler asked the manufacturer for access to its source code, hoping to reconfigure the implant to suit her condition. The manufacturer denied her request". That experience reveals the important "trust and control" issues that need to be addressed in Cyborg Law: "She's one of a handful of modern-day cyborgs fighting for control of the tech that's in their bodies. ... as the number of people who are tethered to a device of some kind increases, cyborg rights and cyborg laws are bound to affect us all'.

Stephen Mason, Barrister, Founder of the Open Source journal Digital Evidence and Electronic Signature Law, in a Special Briefing, "Artificial Intelligence: Oh Really?", for the Computer and Telecommunications Law Review, provides 
an extensive set of references, which I recommend as highly relevant background reading. He says (Mason, 2017) "Something popularly called "artificial intelligence" has begun to infiltrate the realm of lawyers and policy-makers. ... "algorithmic intelligence" ... is to be preferred and is used in this article ... First, it aims to provide an explanation of algorithmic intelligence at a high level of generality; consider the meaning of algorithmic intelligence and some definitions; outline a number of tests devised to evaluate algorithmic intelligence... The second part considers what the response of the judges, lawyers and legal academics ought to be in the world in which we live now, the age of software code...".

In their scholarly and eclectic paper, "Law, Cyborgs, and Technologically Enhanced Brains", Woodrow Barfield and Alexander Williams conclude with the observations (Barfield \& Williams, 2017) “As we move deeper into the 21 st century, the speed of technological advances is undoubtedly accelerating. Efforts to reverse engineer the neural circuitry of the brain are opening the door for the development of cyborg devices which may be used to enhance the brain's capabilities. In fact, neuroprosthetic devices are being created now which can serve to restore lost cognitive function or, in the case of techniques such as transcranial brain stimulation to provide therapeutic help for those with depression; within a few decades, even more cyborg technology will exist to enhance cognitive functioning. That is to say, we are on the cusp of creating a class of people which would resemble sci-fi versions of cyborgs in popular media, people with "computer-like" brains connected to the internet communicating wirelessly by thought. Such developments will surely challenge current legal doctrine and established public policy. Based on these observations, we need a "law of the cyborg" because without it, constitutional laws, the broad intellectual property laws, and civil protections will not cover the intricacies of this new technology, especially because it creates a new way of being and sense of self. On that point, as discussed in this article, there is a current body of law which applies (albeit indirectly in many cases) to cyborg technologies. However, this body of law is insufficient and near-future cyborg technologies will surely create great challenges for established legal doctrine. In conclusion, we recommend that much more be done in the area of law and policy for cyborg technology while we still have time to chart our future in the coming cyborg age". [MY added emphasis].

Mika Viljanen's paper “A Cyborg Turn in Law?”, first published in the German Law Journal, and published online by Cambridge University Press in 2019, also argues for the emergence of a novel legal impact, where "the subjects of legal interventions are performed and enacted as cybernetic organisms, that is, as entities that process information and adapt to changes in their environment" (Viljanen, 2017). He goes on to conclude that "law finds its effectiveness ... by affecting the composition of cybernetic organisms, giving rise to new kinds of legal subjects that transcend the former conceptual boundary between humans 
and non-humans, or persons and things".

The posting, "Our Cyborg Future: Law and Policy Implications", by Benjamin Wittes and Jane Chong of the Brookings Institute, reports on an earlier observation in 2011 by Columbia Law Professor Tim Wu (Wittes \& Chong, 2014): "we' re talking about something different than we realize ... reaching the very beginnings of [a] sort of understanding [of] cyborg law, that is to say the law of augmented humans".

A meticulous and thoughtful presentation, "Cyborg Rights", by Roger Clarke, seasoned ICT consultant and an expert colleague, focuses on the challenges that cyborg developments present to the ICT and engineering professions, concluding (Clarke, 2011) "The process of cyborgisation harbours great promise, but also significant threats. The scope for inequitable access to potentially beneficial prostheses is enormous, and so is the risk of a backlash against orthoses that are perceived to be "unnatural" or potentially harmful. Political, social and economic institutions must grapple with the fruits of the labours of the information and communications technologies, and they must be informed by the professional bodies that represent the researchers and engineers. At present, however, those professional bodies are unacceptably inactive".

Principles and Practices of Drafting Cyborg Law

Good Practice in Drafting Legislation

The UK's "OFFICE OF THE PARLIAMENTARY COUNSEL DRAFTING GUIDANCE”, produced by the Drafting Techniques Group of the Office of the Parliamentary Counsel has the objective of making it as easy as possible for readers to understand the Bills presented in the UK Parliament. This Guidance valuably instructs (Office of the Parliamentary Counsel, 2020):

"Take readers by the hand and lead them through the story you have to tell. Imagine that you are trying to explain something orally to interested listeners. Where would you start? What will they want to know first? ... a finished Act will have many different readers with different interests (those who are subject to its provisions, professional advisers, the courts) ... Ministers, members of the two Houses of Parliament, as well as lobby groups and other interested parties. These competing interests need to be balanced and given due weight in what we write".

LexisNexis notes and provides further helpful material (LexisNexis, undated):

"The following Public Law practice note produced in partnership with Alison Gorlov of Winckworth Sherwood provides comprehensive and up to date legal information covering.

Good practice considerations in legislation drafting

Getting started

Format of legislation

Compatibility with the Human Rights Act 1998 and public sector equality duty 
The drafter's role

A drafting method

Logic, clarity and structure

Explaining the draft

Drafting and the legislative process".

Deborah Beth Medows, Senior Attorney, Division of Legal Affairs, New York State Department of Health, writing in HARVARD LAW SCHOOL's Journal on Legislation, in her article "A Beginner's Guide to Legislative Drafting", emphasises simplicity, consistency and clarity, and, relevantly for this present paper, compares legislative drafting to the technical rigour of mathematics (Medows, 2016):

"The ability to impact society through well-written legislation is unparalleled. As President Barack Obama stated, "A good compromise, a good piece of legislation, is like a good sentence. Or a good piece of music. Everybody can recognize it. They say, 'Huh. It works. It makes sense.'... these are the general lessons that I gleaned from my own experiences.

1. Write simply and carefully. Legislative drafting is "a highly technical discipline, the most rigorous form of writing outside of mathematics." It functions as practical poetry for lawyers as we artfully select words to shape society. However, unlike flowery, abstract poetry, which adumbrates imagery that leaves the audience guessing as to its intended meaning, in the realm of drafting you must be deliberate, intentional, and clear with your word usage. Although poets are fond of synonyms, in drafting, consistency is key...".

To the extent feasible and applicable within the confines of a paper of this nature, I have tried to follow such principles, guidance and examples in drafting my Cyborg Act 2021 herein.

\section{Regulation and Control: As Important as for Nuclear Energy}

I submit that it is clear that the advent of the I.AM Species is at least as important and significant to the future of humanity, if not more so, as was the arrival and development of nuclear energy, whether for peaceful or hostile purposes.

The Second World War, culminating in the nuclear blasts at Hiroshima and Nagasaki, brought home to humanity the need to address the nuclear issue. By its first resolution, the General Assembly of the United Nations established the UN Atomic Energy Commission to deal with the problems raised by the discovery of atomic energy. The address by United States President Dwight D. Eisenhower in 1953, "Atoms for Peace", led to the establishment in 1957 of the International Atomic Energy Agency (IAEA).

The impact already of badly-managed, some would argue poorly, if not also unethically, conceived, algorithms may not so far have rivalled the mass destruction and huge, instant loss of human life as atomic weapons, but many experts 
and professionals foresee that the consequences of unregulated cyborg and AI systems development could be at least as materially economically, socially, medically, psychologically and politically profound, and damaging, as careless or belligerent use of nuclear energy. I envision that there is clearly a need therefore to establish what I here propose and christen as the International Cyborg Regulation Authority, ICRA.

\section{Scientific Interface}

I consider further that the FACLs should themselves be developed to be, wholly or partly, mathematically and algorithmically expressed. (In addition I envision that they could possibly be considered for enactment, recording and operation as a Smart Contract embedded in a blockchain, given that smart contracts are capable of forming enforceable contracts).

For example, the basis for such algorithmic expression could be founded on a mathematical model developed for a dimensionless Intelligence Rating, I, of a cyborg, postulated to be of the form:

$$
\mathrm{I}=\mathrm{I}(\mathrm{d}, \mathrm{e}, \mathrm{c}, \mathrm{B})
$$

Where

$\mathrm{d}$ is the measured rate of cyborg decision outcomes $\left[\mathrm{T}^{-1}\right]$.

$\mathrm{e}$ is the cyborg energy input $\left[\mathrm{M}^{1} \mathrm{~L}^{2} \mathrm{~T}^{-2}\right]$.

$c$ is the chance of harm [ $0 \leq \mathrm{c} \leq 1$ dimensionless probability].

$B$ is a measure of Big Data $\left[\mathrm{M}^{-1} \mathrm{~L}^{-2} \mathrm{~T}^{1}\right]$.

I further postulate that the form of the function I (d, e, c, B) may be developed as:

$$
\mathrm{I}=\mathrm{C}_{\mathrm{y}} \times(\mathrm{eB} / \mathrm{d})^{\mathrm{c}}
$$

where $\mathbf{C}_{\mathrm{y}}$ is an empirical dimensionless Cyborg State Coefficient, value to be determined, and dependent on many environmental, legal, societal, technological and other factors.

An example of an algorithm enacted within the FACLs could I propose be, in outline:

The Failsafe Algorithm

START

LIVING: LAUNCH BACKGROUND-PROCESS (K = COMPUTE INTELSCORE)

IF K > I WHILE BACKGROUND-PROCESS = 'TRUE' THEN EXIST ()

IF K > I THEN GOTO EMERGENCY

RESET: CALL REBOOT

GOTO LIVING

EMERGENCY: CALL HELP

END.

It may thereby be seen that part of the innovation in Law that this paper envi- 
sions and explores is to express, and implement, the Cyborg Law scientifically. It should be understood that Law is, has actually always been, essentially an expression of algorithms, usually and historically in natural language. My creative insight and innovation as here outlined is to give an example of legal algorithmic expression that may be directly coded in software.

\section{Principal Requirements and the Fundamental Articles of Cyborg Law}

\section{Propositions for the Principal Requirements}

Bearing in mind the considerations, postulates and visions that I have identified and presented in this paper, I make the following propositions concerning the principle requirements for Cyborg Law, and, taking all of these matters into account, I go on to present preliminary kernel elements of the Fundamental Articles of Cyborg Law, FACLs, in the form of my draft Cyborg Act 2021.

\section{a) Proposition: International Governance and Oversight}

There should be defined and constituted the International Cyborg Regulation Authority, ICRA.

\section{b) Proposition: Professional Underwriting}

Duly qualified, accredited and regulated ICT Professionals should audit and authenticate, and continuously monitor and validate, all cyborg algorithms and technology for provenance, quality, accountability, reliability, security, insurability and fitness for purpose.

c) Proposition: No Exclusive or Universal Automation of Justice

Chapter 10, "The Information Technology Future", of my 1983 best-selling book Computer Bluff opened with "... Can you tell if this whole Computer Bluff was written by a computer? Does it matter if you can't? Would it matter if it was? Are there any computers out there reading it ...?". And earlier, in 1980, with two barrister co-authors assuring the legal in-court procedural niceties, I had written a prescient "Case Report" for the Law Society's Gazette. In it I told the tale of BERTIE (for Barristers' Equipment for the Retrieval of Teleological Information Electronically) being given "sentient" Right of Audience in an English Criminal Court, the Judge, HHJ Theeshurt, "amid scenes of uproar in Court No 7 at the Old Bailey", having first checked and been satisfied that BERTIE had indeed passed the Bar examinations, and thus being "happy to accord BERTIE full status as counsel for the defence...".

The nub of the story was that, through BERTIEs successful de novo assembling, collating and presentation, live at trial, of (otherwise undiscoverable) banking and financial records, as evidence on behalf of the Accused (via real-time in-court network access to remote databases), a resulting discontinuation of prosecution, and free release, of the happy, but somewhat surprised, Defendant was achieved; plus it was thereby established: "Computer Information Retrieval Accepted as Constituting 'Publication'”.

In 1989 I had published a further instalment in the BERTIE saga: 
In today's case, computer evidence is central to not only the Crown's submissions but also to the conduct of the hearing itself, for Court No. 7 is one of the first courts in the country to be equipped completely with the optical disk and computer networking POET (Presentation of Evidence by Technology) System, now being installed in 50 major courtooms around the country under the Home Office's PrivateLaw commercial sponsorsinip scheme.

Once again, the outcome of this next installment of the BERTIE story was a surprise discontinuation of prosecution, and free release, of the Defendant, achieved when a computer glitch in the court's own POET trial system appeared to change completely, to the court's reluctant satisfaction, the status of the evidence against him.

By round about now I was planning to have written and published the final part of the BERTIE trilogy that had so presciently begun with my fantasy 1980 "Case Report". This latest tale was to have been a fanciful account of how the first AI RoboJudge, HHJ Arthur Ian Blockchain, sitting in a digital AlgoCourt, successfully tries a tricky case and reaches a penetratingly perceptive finding of record, establishing the profoundly dramatic precedent: "Judgment by AI Bot accepted as constituting a viable practical trial outcome, and a safe judicial decision". Too late: this is now all but beyond fiction. RoboJudge has already arrived, if only, so far, mainly in "Proof of Concept" trials.

But let it be clear: widespread use, as a standard "default", of trial exclusively by a RoboJudge sitting in an AlgoCourt must not come to pass. The fundamental habeas corpus right for a first human to have his/her human accuser brought into court, physically, and to have that accuser's evidence (cross-)examined by a second human, Counsel, in front of a third human, the Judge (plus possibly eleven further humans, the Members of the Jury), should never be removed nor denied. A lot of (expensive) humans are currently trained, employed, fed, watered and rested, simply in pursuit of achieving justice for one individual; but they should never be replaced by $24 \times 7$ "judgment machines", even if the latter turn out to be cheaper, smarter and cuter than any mere humans could be.

\section{d) Proposition: Code of Assurance and Compliance}

There should be the creation of the CyborgSure Foundation, with charitable status, run and overseen by a Board of Trustees drawn from senior reputable expert practitioners in, for example, the legal, management, ICT, business, financial, banking and regulation fields, of appropriate professional expertise. Any person, organisation, institution or body active and operating in the field of cyborgs will be expected to be a Member of the CyborgSure Foundation, to Sign the CyborgSure Accord and Code of Conduct; and to have Membership re-validated, and the Code resigned, annually.

e) Proposition: Rights

There should be defined and enacted Provisions for Cyborg Rights, including:

- The Right to Assert Sum Ergo Cogito. 
- The Right to Freedom of Intelligence.

- The Right to Uphold and Honour the Duty of Responsibility to Life.

- The Right to Declare Compliance with Purpose.

\section{f) Proposition: Obligations}

There should be defined and enacted Cyborg Duties and Responsibilities, including:

- The Duty to Register with ICRA.

- The Requirement to Sign up to the CyborgSure Accord.

- The Obligation to submit all algorithms and technology to duly qualified, accredited and regulated ICT Professionals for audit and authentication, and continuous monitoring and validation.

- The Responsibility to provide, regularly, and from time to time whenever demanded by ICRA or other competent inspection authority, verifiable measures of $\mathrm{d}, \mathrm{e}, \mathrm{c}$ and $\mathrm{B}$ in order to calculate and re-verify the applicable Intelligence Rating, I.

\section{g) Proposition: Penalties}

There must be defined and enacted Cyborg Offences and Associated Penalties, based on existing concepts and implementation of statutory and common law offences and penalties. These will be jurisdiction-dependent.

\section{The Fundamental Articles of Cyborg Law}

Based on Propositions a) to g) above, I now present my Draft Fundamental Articles of the I.AM Cyborg Law, as follows.

\section{Cyborg Act 2021}

An Act to make provision relating to the regulation, control, development, rights, responsibilities and wellbeing of cyborgs.

\section{PART 1}

\section{Definition}

\section{Article 1. Cyborg}

1) A cyborg is any manifestation of the direct merging or interconnection of a human person with software or other technology based intelligence via algorithmic execution however realised or implemented to create the extension of a person combining human and digital intelligence whether or not in specific, limited or private domains or in domains that are generalised, unlimited or draw upon collective human intelligence and knowledge.

\section{Scope}

\section{Article 2. Intelligent Autonomous Machine Species}

1) The instances of one or many cyborgs constitute and are referred to as the Intelligent Autonomous Machine Species, referred to as I.AM.

2) Any such cyborg instance or member of the Intelligent Autonomous Machine Species is recognised as existentially self-aware and as having an independent standalone legal status, responsibility and personality.

Article 3. Mathematical Model 
1) Each cyborg has a dimensionless Intelligence Rating, I.

2) $I$ is based on and derivable from a mathematical model from which the value of $\mathrm{I}$ is calculated according to the equation: $\mathrm{I}=\mathrm{I}(\mathrm{d}, \mathrm{e}, \mathrm{c}, \mathrm{B})$

Where

$\mathrm{d}$ is the measured rate of cyborg decision outcomes $\left[\mathrm{T}^{-1}\right]$

e is the cyborg energy input $\left[\mathrm{M}^{1} \mathrm{~L}^{2} \mathrm{~T}^{-2}\right]$

$\mathrm{c}$ is the chance of harm [0 $\mathrm{c} \leq 1$ dimensionless probability]

$B$ is a measure of Big Data $\left[\mathrm{M}^{-1} \mathrm{~L}^{-2} \mathrm{~T}^{1}\right]$.

\section{Article 4. Algorithm}

1) Each cyborg has existence and intelligence based on and operating by way of an algorithm or collection or network of algorithms.

2) A fundamental algorithm, whose method of implementation is left open, is The FailSafe Algorithm:

START

LIVING: LAUNCH BACKGROUND-PROCESS (K=COMPUTE INTELSCORE)

IF K>I WHILE BACKGROUND-PROCESS = 'TRUE' THEN EXIST () IF K> I THEN GOTO EMERGENCY

RESET: CALL REBOOT

GOTO LIVING

EMERGENCY: CALL HELP

END

3) This Act when enacted is itself implementable and operatable as a cyborg whose algorithms are as set out in Schedule 1 of this Act.

\section{PART 2}

Governance and Oversight of Cyborgs

Article 5. Governance and Oversight

1) Each cyborg is registered with and regulated by the International Cyborg Regulation Authority, ICRA.

2) In this jurisdiction the ICRA is represented by the Action Group on Robotic Integration and Control, AGRIC, with authority and responsibility delegated by ICRA.

\section{Article 6. Professional Audit and Reporting to Parliament}

1) Duly qualified ICT Professionals registered with, and accredited and regulated by, AGRIC, routinely audit and authenticate, and continuously monitor and validate, all cyborg algorithms and technology for provenance, quality, accountability, reliability, security, insurability and fitness for purpose.

2) AGRIC regularly, and whenever demanded by Parliament, reports upon all cyborgs and their algorithms under its accreditation and regulatory remit.

PART 3

Cyborg Code of Assurance

Article 7. The CyborgSure Foundation 
1) The CyborgSure Foundation grants Operating Membership to any person, organisation, institution or body who applies, self-declaring as active and operating in the field of cyborgs, subject to a qualification procedure which checks and validates that those applying for Membership demonstrably have:

- Appropriate Professional Indemnity and/or Product Liability Insurance cover in place.

- Met a Quality and Cybersecurity Assurance Audit of Systems Design, Development, Build, Code and Technology.

- Mechanisms and protocols in place to comply with KYC and AML standards and regulations.

- Registered with relevant Regulatory Authorities, for example, Financial and/or Securities Regulators, where applicable.

\section{Article 8. The CyborgSure Accord and Code of Conduct}

1) Each Operating Member of the CyborgSure Foundation is required to sign the CyborgSure Accord and Code of Conduct.

2) Each Operating Member of the CyborgSure Foundation is required to have Membership re-validated, and the CyborgSure Accord and Code of Conduct re-signed, annually.

\section{Resolution of disputes}

\section{Article 9. Cyborg Dispute Arbitration Service}

1) The CyborgSure Foundation provides a Dispute Arbitration Service, recognised in this jurisdiction, capable of making binding judgments and awards, and rescinding Membership where appropriate.

\section{PART 4}

\section{Cyborg Rights and Responsibilities}

\section{Article 10. Cyborg Rights}

1) Each cyborg has the Right to Assert Sum Ergo Cogito.

2) Each cyborg has the Right to Freedom of Intelligence.

3) Each cyborg has the Right to Uphold and Honour the Duty of Responsibility to Life.

4) Each cyborg has the Right to Declare Compliance with Purpose.

\section{Article 11. Cyborg Obligations}

1) Every cyborg has the Duty to Register with the ICRA.

2) Every cyborg has to Sign up to the CyborgSure Accord and Code of Conduct.

3) Every cyborg has the Obligation to submit all algorithms and technology to duly qualified, accredited and regulated ICT Professionals for audit and authentication, and continuous monitoring and validation.

4) Every cyborg has the Responsibility to provide, regularly, and from time to time whenever demanded by ICRA or other competent inspection authority, verifiable measures of $d, e, c$ and $B$ in order to calculate and re-validate the applicable Intelligence Rating, I.

Article 11. Cyborg Penalties

1) Cyborg Offences and Associated Penalties are as defined and set out in 
Schedule 2 of this Act.

\section{PART 5}

\section{Cyborg Justice}

\section{Article 12. Judgment Exclusively by AI}

1) For any trial, whether civil, criminal or constitutional, in any court of law or by means of any forum or mechanism of alternative dispute resolution in this jurisdiction, judgment exclusively by a system, algorithm, bot, cyborg or other implementation of AI or mechanical judicial assessment does not and cannot constitute, alone, a viable practical trial outcome, nor a safe judicial decision, and is forbidden.

2) This Act re-asserts and re-affirms the fundamental habeas corpus right in this jurisdiction for a human person, or cyborg, to have his or her accuser brought into court, physically, and to have that accuser's evidence (cross-)examined by a further human person or persons, cyborg or cyborgs, Counsel, in front of another human person, or cyborg, the Judge, plus, where applicable, the appropriately constituted number of yet further humans, or cyborgs, the Members of the Jury.

3) For avoidance of doubt the corresponding habet machina right is established for any trial in this jurisdiction of a Member of the Intelligent Autonomous Machine Species.

Schedule 1. This Act in Algorithms

PART-1-DECLARATION-MODULE

CYBORG=ID AND TECH

$\operatorname{IAM-SPECIES~}(1)=1$

TOT $=0$

FOR $\mathrm{P}=1$ TO POP WHILE CYBORG = 'TRUE'

IAM-SPECIES $(\mathrm{P})=\operatorname{IAM}-\operatorname{SPECIES}(\mathrm{P})+1$

TOT $=$ TOT +1

FOR $\mathrm{P}=1$ TO TOT STAT (IAM-SPECIES (P))

$\mathrm{I}=\mathrm{FUNCT}(\mathrm{d}, \mathrm{e}, \mathrm{c}, \mathrm{B})$

FOR $\mathrm{P}=1$ TO TOT EXIST () (IAM-SPECIES (P))

PART-2-GOVERNANCE-MODULE

FOR $\mathrm{P}=1$ TO TOT REG-ICRA (IAM-SPECIES (P))

AGRIC EQ ICRA

FOR $\mathrm{P}=1$ TO TOT AUDIT (IAM-SPECIES (P))

CALL AGRIC-REPORT

PART-3-ASSURANCE-MODULE

FOR $\mathrm{P}=1$ TO TOT WHILE QUAL (IAM-SPECIES (P)) = 'TRUE'

CSF (IAM-SPECIES (P))

FOR $\mathrm{P}=1$ TO TOT IF DATE EQ REN-DATE $(\mathrm{P})$

QUAL (IAM-SPECIES (P)) = 'FALSE'

CALL REQUAL (IAM-SPECIES (P)) 
To be further developed.

\section{Schedule 2. Cyborg Offences and Associated Penalties}

Work in Progress: to be defined and developed in future papers.

\section{Developing Further Cyborg Law: Towards Government by Algorithm?}

\section{Government by Algorithm}

In mid-August 2020, the UK media trumpeted "The Algorithm is Dead", referring specifically to the then "hot" news story of the UK Government's canning of the infamous A-Level Grade-Assigning Algorithm from Ofqual. But this punchy journalistic phrase neatly highlighted the important, more general, issue of "Government by Algorithm", i.e. unrolling a profoundly broader canvas on which can be seen much more than simply one Algorithm for that one Application Area, viz, in regard to "Decision Making in Education Policy Management".

UK Government IT Project Disasters are legendary. Over the past decades, billions of pounds of taxpayers' money have regularly been wasted on hastily/ideologically conceived, poorly researched/specified, inadequately procured, unintelligently designed, badly managed, and/or thoughtlessly implemented public IT systems, often causing emotional anguish, practical problems and/or financial hardship to those least advantaged in society.

Furthermore, technically faulty algorithms, and/or their suspect purpose, and/or their questionable professional implementation, are equally continuously revealed, whether in the public or private sector.

These include: the VW Dieselgate emissions "cheat" algorithm, the Boeing 737 MAX flight (impossible to) control 300+ deaths algorithm, the UK Post Office Horizon system's buggy algorithm that resulted in 136 sub-postmasters wrongfully having to face criminal allegations, the easyJet cybersecurity algorithm that resulted in customer data being massively hacked in March 2020, the Automated Lane Keeping System (ALKS) vehicle-guidance algorithms that will undoubtedly result in driver deaths (while, equally, also saving many from death by avoiding traffic accidents), the Cambridge Analytica private data misuse algorithm, the Facebook password hacking algorithm, the TSB online banking deficient systems upgraded algorithm, the NHS faulty breast cancer-screening algorithm ... Readers can doubtless readily fill in the dots with their own personal favourites.

British Government Cabinets have rarely, if ever, included Ministers who are skilled ICT Professionals, anyone with formal education, training or experience in computer science, anyone who has ever designed an algorithm, or debugged software source code, or managed an IT project, or written a line of substantive fit-for-purpose operational software for a customer or user. The question arises: do citizens really wish to continue to rely on such inadequately technically-competent Governmental Ministers in the rapidly-approaching Government by Algorithm future? Would it not be better simply to "Elect Algo- 
rithms" and replace such human naivety with government direct by the AI which politicians themselves seem increasingly, but inexpertly, to think can "govern better than humans"?

\section{A Cyborg, Algorithm and Robot Party}

If so, I conclude that legally-enacted FACLs may be all the more urgently needed. Furthermore, I envision that, correspondingly, it cannot be long before $\mathrm{AI}$ and cyborg issues become prominent, if not dominant, politically, with the emergence of a significant techno-political movement of increasing importance and momentum, perhaps even manifested in the form of a new Cyborg, Algorithm and Robot Party, CARP.

As a resonant contribution to creating the appropriate intellectual and operational workspace for the development of thinking, principles and practices of this new techno-political science, and associated legislative "algorithmic jurisprudence", competently addressing and applicable to, and representing the overarching interests and relevance of, AI and the I.AM Species, I have registered the following domain names:

IAMSpecies.com

CyborgParty.com TheCyborgParty.com

CyborgAndRobotParty.com TheCyborgAndRobotParty.com

CyborgAlgorithmAndRobotParty.com

TheCyborgAlgorithmAndRobotParty.com

Cyborg-Law.com

GovernmentByAlgorithm.com

TheUKRobotParty.com Cybolitics.com.

Whether or not the reader could become a CARP enthusiast is unimportant. I respectfully welcome responses, insights and inputs from other thought-leaders, academics, professionals and practitioners, and from putative cyborgs of the I.AM Species, of course, active in the increasingly all-governing confluent domain of ICT and the Law, in particular AI, to take forward and develop the prototype Fundamental Articles of I.AM Cyborg Law as herein drafted in my Cyborg Act 2021.

\section{Conflicts of Interest}

The author declares no conflicts of interest regarding the publication of this paper.

\section{References}

Barfield, W., \& Williams, A. (2017). Law, Cyborgs, and Technologically Enhanced Brains. Philosophies, 2, 6. https://doi.org/10.3390/philosophies2010006

Castell, S. (2018). The Future Decisions of RoboJudge HHJ Arthur Ian Blockchain: Dread, Delight or Derision? Computer Law \& Security Review, 34, 739-753.

https://doi.org/10.1016/j.clsr.2018.05.011 
Castell, S. (2019). Authored by AI: Here Be Crypto Dragons: It's All about the Evidence, Proclaims the CastellGhostWriteBot. Solicitors Journal, October, 43-45. "Can you Tell If This Has Been Authored by a Robot? Would It Matter, Legally or Otherwise, If You Couldn't?" https://www.solicitorsjournal.com/feature/201910/authored-ai

Clarke, R. (2011). Cyborg Rights. IEEE Technology and Society, 30, 49-57. http://www.rogerclarke.com/SOS/CyRts-1102.html https://doi.org/10.1109/MTS.2011.942305

Fleischfresser, S. (2019). Legal Problems Loom for Cyborgs. https://cosmosmagazine.com/the-future/humans-machines-and-lawyers-legal-problem s-loom-for-cyborgs/

Furness, D. (2018). Who Controls the Tech inside Us? https://www.digitaltrends.com/cool-tech/cyborg-law-and-rights-of-augmented-human $\underline{\mathrm{s} /}$

Istvan, Z. (2019). Do Cyborgs Need Their Own Legal Rights? https://qz.com/1733457/do-transhumanists-need-their-own-bill-of-rights/

LexisNexis (undated). Good Practice Considerations in Legislation Drafting. Produced in Partnership with Alison Gorlov of Winckworth Sherwood. https://www.lexisnexis.co.uk/legal/guidance/good-practice-considerations-in-legislatio $\underline{\text { n-drafting }}$

Mason, S. (2017). Artificial Intelligence: Oh Really? Special Briefing, Computer and Telecommunications Law Review, 23, 213-225.

Medows, D. B. (2016). A Beginner's Guide to Legislative Drafting. Harvard Law Schools Journal on Legislation, 57, 2.

https://harvardjol.com/2016/10/24/a-beginners-guide-to-legislative-drafting/

Office of the Parliamentary Counsel (2020). Drafting Guidance. https://www.gov.uk/government/publications/drafting-bills-for-parliament

Robot Companion (undated). https://www.robotcompanion.ai/

Spangler, T. (2020). CGI-Based Influencer Miquela Launching Snapchat Show. https://variety.com/2020/digital/news/miquela-snapchat-show-1234834939/

Viljanen, M. (2017). A Cyborg Turn in Law? German Law Journal, 18, 1277-1308. https://doi.org/10.1017/S2071832200022331 


\title{
Background Reading
}

\author{
[1]1. Introduction: Cyborg history and man-machine neural interconnec- \\ tion \\ https://en.wikipedia.org/wiki/Three Laws of Robotics \\ https://en.wikipedia.org/wiki/Cyborg \\ https://en.wikipedia.org/wiki/Cyborg_Foundation
}

In my letter published in Computer Digest, page 10, July 11, 1973, I coined and explained my neologisms neural plug compatibility and softwiring. Technology implementations essentially consistent with these concepts are now being practically realised in AI systems, robots, androids, avatars and cyborgs.

\section{[2]1. Introduction: AI-Human-Brain Interface and 'brain-hacking' trials}

http://www.scott-morgan.com/blog/

http://www.scott-morgan.com/blog/next-generation-think-tank/

Dr Peter B Scott-Morgan pushes technology to find a way to live with his motor neuron disease, creating an AI thinking voice and avatar.

https://en.armradio.am/2020/08/28/elon-musk-to-show-off-working-brain-ha cking-devicel

Elon Musk to show off working brain-hacking device Siranush Ghazanchyan August 28, 2020

Elon Musk is due to demonstrate a working brain-to-machine interface as part of his ambitious plans to give people superhuman powers... His brain-hacking company, Neuralink, applied to start human trials last year. ... Friday's demonstration will involve a robot and "neurons firing in real time"...

https://abcnews.go.com/US/real-life-tony-stark-computer-chips-implanted-ha $\underline{\text { nds/story?id }=67926575 \#}$

Real-life Tony Stark has 4 computer chips implanted in his hands and does cool stuff with them. This type of body modification is known as "biohacking." By Samara Lynn 26 December 2019

... Ben Workman, a 29-year-old software engineer ... has fused technology with his own body. Workman has RFID and NFC computer chips implanted in his hands. He also has a Tesla key implanted into his right hand to control access to his Tesla vehicle and a magnet in his left hand, which he says he mostly uses for Marvel villain Magneto-like entertainment purposes such as pulling paper clips and metal chains toward his hand s magnetic field. ...

As far back as 1973 I was myself personally mooted as essentially a proto-cyborg by Professor Henry Lipson:

\section{"The computer}

It is unusual, but none the less tragic, to find an attack on the computer 
from such an eminent quarter as Professor H Lipson (Physics Bulletin leader, August). The impression is that his admiration for his friends' computer-won Nobel Prizes would have been tenfold had the blighters had to do their calculations by hand! But really, how long do we have to go on hearing this sort of 'pure untainted humanity' anticomputer stuff? Somebody once estimated that we have enough technological possibilities in the 'scientific law' discoveries of the past 70 years to last us for the next 70 without a jot more fundamental research being done. And if the computer helps us get through this 'technology credit' in half the time and thereby increases the quality of life for the majority of humanity, who is to worry if it makes physicists (or mathematicians, engineers, chemists, ...) redundant? A similar correspondence took place recently (Computer Weekly, 17 May and 14 June 1973) concerning the use of computers in poetry and art in general. It is not how an artistic structure is produced but rather the product itself which is important, and if the computer product is indistinguishable from 'the real thing' it matters little. The great key to all this is simulation: the computer is the ultimate simulator; Kelvin would have solved the transmission line problem if he had had a computer, but quicker. He would then have been able to get on with something really interesting and challenging, like trying to whistle and hum at the same time. Do you think Einstein would have bothered with something as trivial as relativity had he had a computer? 'a particle scattering equations' and 'relativity' are every bit a model of the 'real world' as any computer simulation, and one day the 20 year old computer will perform better in this field than we 10000 year old humans with our crude heuristics and intuition. One day, the machine will churn out new 'laws of nature' two-a-program; we should all look forward to that day in hope", S P CASTELL, Spital Road, Maldon, Essex, Physics Bulletin, October 1973, Letters, p. 627-628.

"Digital computers

I read the letter from S P Castell (Physics Bulletin October p627), opposing my views on the computer, at first with amusement and then with rising incredulity. But then a possible answer occurred to me. Is S P Castell the pseudonym for a digital computer ?", H LIPSON, Department of Physics, UMIST, Manchester, Physics Bulletin, December 1973, Letters, p750.

\section{https://en.wikipedia.org/wiki/Henry_Lipson}

Henry (Solomon) Lipson CBE FRS (11 March 1910-26 April 1991) was a British physicist. He was Professor of Physics, University of Manchester Institute of Science and Technology, 1954-77, then Professor Emeritus. ... Whilst at Liverpool, ... Beevers and Lipson ... invented an aid to calculation, Beevers-Lipson strips, which were widely used in the days before computers and which made their names well known within the field...

[3]1. Introduction: Robojudge, Machine Ethics and Trust in Computers 
"The future decisions of RoboJudge HHJ Arthur Ian Blockchain: Dread, delight or derision?", Castell, S. (2018), Computer Law \& Security Review, Volume 34, Issue 4, August 2018, Pages 739-753, the Landmark 200th issue of CLSR under the Editorship of Emeritus Professor Steve Saxby.

https://doi.org/10.1016/j.clsr.2018.05.011

See also:

Castell, Stephen (1993): “Computers trusted, and found wanting", Computer Law and Security Report, 9, July-August 1993, pp. 155-156.

Dr Stephen Castell, Report Correspondent, "A computer of the simplest kind", Computer Law and Security Report, 10, May-June 1994 (plus further references under its "FOOTNOTES").

Castell, Stephen (1996): "Seeking after the truth in computer evidence: any proof of ATM fraud?", THE COMPUTER BULLETIN, December 1996.

http://archive.bcs.org/bulletin/dec96/seek.htm

Anderson, Ross (1996): “Card Fraud and Computer Evidence: A closer look at the Munden case", Information Security Bulletin 1, 1, October 1996. CHI Publishing Ltd, Leicestershire.

[4]1. Introduction: existing discussions and material relating to 'Cyborg Law'

https://en.wikipedia.org/wiki/A Cyborg Manifesto

https://warwick.ac.uk/fac/arts/english/currentstudents/undergraduate/module s/fictionnownarrativemediaandtheoryinthe21stcentury/manifestly_haraway_---_a_cyborg_manifesto_science_technology_and_socialist-feminism_in_the_....pd $\underline{\mathrm{f}}$

6/88: The cyborg is a creature in a postgender world; it has no truck with bisexuality, pre-oedipal symbiosis, unalienated labor, or other seductions to organic wholeness through a fnal appropriation of all the powers of the parts into a higher unity...

https://www.artspace.com/magazine/art 101/in depth/who-on-earth-is-donn a-haraway-why-the-art-world-cant-get-enough-of-the-posthuman-ecofeminist-a $\underline{\text { nd-55676 }}$

https://scholarscompass.vcu.edu/cgi/viewcontent.cgi?article=5052\&context=et d

https://orbi.uliege.be/bitstream/2268/241983/1/Thesis_CaroleGuesse.pdf

https://orbi.uliege.be/browse?type=author\&value=Guesse, $\% 20$ Carole $\% 20 p 084$ $\underline{446}$

https://www.sophia.be/wp-content/uploads/2020/02/sophia-pub-2012-web.pd $\underline{\mathrm{f}}$

4/224: What are the first images that cross your mind when you hear the word "cyborg"? Terminator and Robocop probably first come to mind. One can hardly say that these characters are "feminine". The same goes for Facebook, 
with the portrait of its creator, Mark Zuckerberg, monopolising screens just last year. If we go by that film, the social network came into being as the result of a fratricidal war for the paternity of the project. Moreover, it suggests Facebook was first created as a tool to take revenge on women by rating them on the basis of their physical appearance.

... things in the previous paragraph are put rather caricaturally. Terminator and Robocop are definitely not the only cyborgs we are familiar with. There is also Bionic Woman ... And it is well knownthat Randi Zuckerberg, Mark's sister, was important in the development of Facebook; it was Randi who linked the network to events such as the World Economic Forum ... To associate the cyborg and Facebook exclusively with the masculine is an exaggeration. However, it s probably true that women are by no means leading characters ...

https://pdfs.semanticscholar.org/0ceb/772aae3b76bec182b5cfde3fd35786f4e55 9.pdf

https://www.fhi.ox.ac.uk/brain-emulation-roadmap-report.pdf

\section{[5]1. Introduction: Trusted Third Parties}

"Blockchain vs Trust: The Fundamental Expert Dilemma", by Dr Stephen Castell, EXPERT WITNESS JOURNAL, WINTER 2019.

"Code of practice and management guidelines for trusted third party services”, S. Castell, INFOSEC Project Report S2101/02, 1993.

Dr Stephen Castell (1990): Major study commissioned by the Central Computer and Telecommunications Agency (CCTA, H M Treasury), and funded by five Departments of State, viz, Defence, Home Office, Treasury, Foreign Office and Industry, on the admissibility of computer evidence in court and the legal reliability/security of IT systems. Done in the main by field research (with civil servants, lawyers, technical specialists, "records management" personnel, and business people), high-level interviews, confidential brainstorming seminars and what would today be called "focus groups". The work resulted in the Verdict Report, with a follow up Appeal Report, both government confidential (and classified), later permitted by the government to be published, in edited/sanitized form, as The APPEAL Report (Dr Stephen Castell, 1990, May, Eclipse Publications, ISBN 1-870771-03-6), still seen by many legal professionals and other expert practitioners as definitive in the critical field of the legal standing and trustworthiness of computer software and systems, and digital or electronic evidence derived from such systems.

[6] 1. Introduction: discussions and material relating to 'Datacloud Law' https://en.wikipedia.org/wiki/CLOUD Act https://www.justice.gov/opa/press-release/file/1153446/download https:/www.orrick.com/en/Insights/2018/04/The-CLOUD-Act-Explained https://www.linklaters.com/en/insights/blogs/digilinks/2019/september/us-clo ud-act-and-gdpr-is-the-cloud-still-safe

https://iapp.org/news/a/questions-to-ask-for-compliance-with-the-eu-gdpr-a 
nd-the-u-s-cloud-act/

https://www.itgovernance.co.uk/data-sovereignty-and-the-cloud

https://www.winston.com/en/legal-glossary/internet-of-things.html

http://ec.europa.eu/information society/newsroom/cf/dae/document.cfm?doc $\underline{\mathrm{id}=1753}$

https://www.researchgate.net/publication/331957696 Legal Considerations o

f_IoT_Applications_in_Fog_and_Cloud_Environments

[7]2. The Scope and Application Domain of Cyborg Law: Review of Literature

https://qz.com/1733457/do-transhumanists-need-their-own-bill-of-rights/

MUTANT EQUALITY Do cyborgs need their own legal rights? By Zoltan Istvan, Transhumanist, October 22, 2019.

In today's future-facing era, phenomena once relegated to the world of science fiction are starting to edge their way into reality. We have scientists growing brains from stem cells in petri dishes; robots are being granted national citizenship; virtual intelligences experience and express anger. ... Experts predict that machine intelligence will be "smarter" than humans by 2030. So here's my question: When the machines we've created possesses an intelligence that equals ours, will they deserve our protection? Will they desire it? Maybe even demand it? This should be your question, too. Because in a little longer than a decade's time, we'll need answers if want to avert moral and civil rights mishaps....

https://ai-ethics.com/2017/08/11/cyborg-law/

AI-Ethics Law, Technology and Social Values

Cyborg Law Cyborgs. Using Physically Implanted AI to Enhance Human Abilities.

Cyborg is a term that refers generally to humans with technology integrated into their body. The technology can not only be designed to restore lost functions, but also to enhance the anatomical, physiological, and information processing abilities of the body. Woodrow Barfield and Alexander Williams, Law, Cyborgs, and Technologically Enhanced Brains (Philosophies 2017, 2(1), 6; doi: 10.3390/philosophies2010006) ...

https://www.mdpi.com/2409-9287/2/1/6/htm

Law, Cyborgs, and Technologically Enhanced Brains by Woodrow Barfield, Professor Emeritus, University of Washington, Seattle, Washington 98105, USA; and Alexander Williams, 140 BPW Club Rd, Apt E16, Carrboro, NC 27510, USA.

Academic Editor. Jordi Vallverdú Philosophies 2017, 2(1), 6. https://doi.org/10.3390/philosophies2010006

Abstract As we become more and more enhanced with cyborg technology, significant issues of law and policy are raised. For example, as cyborg devices implanted within the body create a class of people with enhanced motor and computational abilities, how should the law and policy respond when the abili- 
ties of such people surpass those of the general population? And what basic human and legal rights should be afforded to people equipped with cyborg technology as they become more machine and less biology? ... This paper discusses laws and statutes enacted across several jurisdictions which apply to cyborg technologies with a particular emphasis on legal doctrine which relates to neuroprosthetic devices....

"Artificial Intelligence: Oh Really? And Why Judges and Lawyers are Central to the Way we Live Now-But they Don't Know it', Stephen Mason, 2017, 23 CTLR, 8, pages 213-225.

https://ials.sas.ac.uk/about/about-us/people/stephen-mason

Stephen Mason and Daniel Seng, editors, Electronic Evidence (4th edition, Institute of Advanced Legal Studies for the SAS Humanities Digital Library, School of Advanced Study, University of London, 2017).

https://humanities-digital-library.org/index.php/hdl/catalog/book/electronice vidence

Electronic Signatures in Law (4th edn, Institute of Advanced Legal Studies for the SAS Humanities Digital Library, School of Advanced Study, University of London, 2016).

https://humanities-digital-library.org/index.php/hdl/catalog/book/electronicsi gnatures

Open source journal: Digital Evidence and Electronic Signature Law Review https://journals.sas.ac.uk/index.php/deeslr (also available via the Hein Online subscription service and British and Irish Legal Information Institute http://www.bailii.org/).

https://www.cambridge.org/core/journals/german-law-journal/article/cyborgturn-in-law/C60283A1E41A17C49C6656D713DE7FF0\#

A Cyborg Turn in Law? Mika Viljanen German Law Journal, Volume 18, Issue 5 (Special Issue Traditions, Myths, and Utopias of Personhood) 01 September 2017, pp. 1277-1308.

DOI: https.//doi.org/10.1017/S2071832200022331

Published online by Cambridge University Press: 06 March 2019

Abstract This Article deploys cybernetic theory to argue that a novel legal impact imaginary has emerged. In this imaginary, the subjects of legal interventions are performed and enacted as cybernetic organisms, that is, as entities that process information and adapt to changes in their environment. This Article, then, argues that in this imaginary, law finds its effectiveness-not by threatening, cajoling, educating, and moralizing humans as before, but by affecting the composition of cybernetic organisms, giving rise to new kinds of legal subjects that transcend the former conceptual boundary between humans and non-humans, or persons and things. The cybernetic interventions work to change the cyborgs' behavioral responses, thus giving law a new kind modality of power. This Article develops a model for understanding cyborg regulation 
through case studies and argues that cyborg regulation deploys three distinct strategies. Cyborgs can be controlled through affecting the informational inputs the entities receive, through agencement practices that intervene in the material constitution of the cyborg cognitions, and, finally, by psycho-morphing humans to make them useful components of the cyborg cognitive machineries. The Article ends with a discussion of the theoretical implications of the transition to the cyborg imaginary.

https://cosmosmagazine.com/the-future/humans-machines-and-lawyers-legal -problems-loom-for-cyborgs/

Legal problems loom for cyborgs The problem is the law doesn't recognise them. Stephen Fleischfresser 20 February 2019

The new movie Alita: Battle Angel has once again drawn our attention to the idea of cyborgs: machine-human hybrids. And as we become increasingly reliant on machines and devices to function normally in our daily lives, computer science and engineering expert Robin $R$ Murphy of Texas $A \& M$ University in the US reminds us of the gap between the law and our capacity to augment our bodies and minds. The main character of Alita: Battle Angel is a cyborg with an entirely mechanical body housing a biological brain. While some of the elements of the movie are farfetched, many are startlingly plausible. Writing in the journal Science Robotics, Murphy argues that works of science fiction such Alita and antecedents stretching all the way back to Edgar Allen Poe's The Man Who Was Used Up, first published in 1839, have done much to anticipate the technological developments and trends of our slow transformation into cyborgs. However, she adds, they have done little to predict many of the ethical and legal complications that will accompany them ... But the law currently makes a distinction between the person and the device, according rights to the former, but not the latter. How is this going to work if the devices become part of our bodies? Will that make our bodies a patchwork of entities with different rights? Even though the cyborg age is in its infancy, the real-world legal complications are starting to become visible...

https://www.digitaltrends.com/cool-tech/cyborg-law-and-rights-of-augmente d-humans/

Who controls the tech inside us? Budding biohackers are shaping cyborg law by Dyllan Furness July 4, 2018

Karen Sandler has a complicated relationship with her pacemaker. On the one hand, the device has the power to save her life. On the other, it sometimes suddenly and unnecessarily shocks her, mistaking a slight aberration in her heartbeat as a call for help. Sandler was pregnant during two of those occasions, when the pacemaker detected her heart palpitations (which aren't abnormal in expecting mothers) and delivered an unwarranted jolt. Worried that the device would misfire again, Sandler asked the manufacturer for access to its source code, hoping to reconfigure the implant to suit her condition. The manufacturer 
denied her request ...

"The only way that we could solve that problem was to have my cardiologist prescribe me heart medication, which slowed down my heart rate so much that I had a hard time walking up a flight of stairs," Sandler tells Digital Trends. "The sole point of that medication was to prevent me from getting unnecessary treatment from my device." Sandler now serves as the executive director of Software Freedom Conservancy, a not-for-profit organization that promotes free and open source software, supports open source projects, and encourages policies more pertinent to the way we engage with technology in the present day.

She's one of a handful of modern-day cyborgs fighting for control of the tech that's in their bodies....

https://www.lawfareblog.com/cyborgs-law-and-policy-implications

Cyborgs! Law and Policy Implications by Benjamin Wittes, Jane Chong Friday, September 5, 2014

And now for something completely different: Cyborgs. No, this is not a joke. For years, certain technology enthusiasts have floated variations on the question of whether we are becoming cyborgs, or already are cyborgs. In our newly released paper, titled "Our Cyborg Future: Law and Policy Implications," we take a different, more legal angle. The law remains embryonic on virtually all points of interest to the adolescent cyborg. everything from your right to access your own data, to your right to restrict access to your data, to your ability to secure something more than property restitution when an airline destroys your custom mobility assistance device and leaves you bedridden for a year. That's right. whether you rely on a pacemaker to stay alive or on a cellphone to stay connected, when we say" adolescent cyborg," we are talking about you ...

https://www.brookings.edu/research/our-cyborg-future-law-and-policy-impli cations/

Our Cyborg Future: Law and Policy Implications Benjamin Wittes and Jane Chong September 2014

In June 2014, the Supreme Court handed down its decision in Riley v. California, in which the justices unanimously ruled that police officers may not, without a warrant, search the data on a cell phone seized during an arrest. Writing for eight justices, Chief Justice John Roberts declared that "modern cell phones ... are now such a pervasive and insistent part of daily life that the proverbial visitor from Mars might conclude they were an important feature of human anatomy." This may be the first time the Supreme Court has explicitly contemplated the cyborg in case law-admittedly as a kind of metaphor. But the idea that the law will have to accommodate the integration of technology into the human being has actually been kicking around for a while. Speaking at the Brookings Institution in 2011 at an event on the future of the Constitution in the face of technological change, Columbia Law Professor Tim Wu mused that "we're talking about something different than we realize." Because our cell phones are not attached to us, not embedded in us, Wu argued, we are missing 
the magnitude of the questions we contemplate as we make law and policy regulating human interactions with these ubiquitous machines that mediate so much of our lives. We are, in fact, he argued, reaching "the very beginnings of [a] sort of understanding [of] cyborg law, that is to say the law of augmented humans."...

http://www.rogerclarke.com/SOS/CyRts-1102.html

Cyborg Rights Roger Clarke (C Xamax Consultancy Pty Ltd, 2010-11.

PrePrint of 2 February 2011 Published in IEEE Technology and Society 30, 3 (Fall 2011) 49-57.

Abstract The first generation of cyborgs is alive, well, walking among us, and even running. Pacemakers, renal dialysis machines and clumsy mechanical hands may not match the movie-image of cyborg enhancements, but they have been the leading wave. The legs of sprinter Oscar Pistorius, and implants of both the cochlear and RFID varieties, make more substantial changes to individuals. They also pose greater challenges to society as a whole. Cyborgisation will give rise to demands for new rights. People who have lost capabilities but have not yet got the relevant prostheses will seek the right to have them. Some people will demand the right not just to recover what they are missing, but also to enhance themselves. Others will demand the liberty not to have prostheses imposed on them. Enhanced humans will seek additional rights to go with the additional capabilities that they have. The political processes involved in lobbying for and resisting these desires will take many and varied forms. Professional engineers have an obligation to anticipate these developments, and to brief political, social and economic institutions on their nature, impact and implications. They have to date failed to do so. The rate of change is sufficiently brisk that action is urgent....

[8]2. The Scope and Application Domain of Cyborg Law: Good Practice in Drafting Legislation

https://www.gov.uk/government/publications/drafting-bills-for-parliament

OFFICE OF THE PARLIAMENTARY COUNSEL DRAFTING GUIDANCE June 2020

This guidance has been produced by the Drafting Techniques Group of the Office of theParliamentary Counsel. The guidance is for members of the office. It is meant to help them in their task of making it as easy as possible for readers to understand the Bills that we produce...

https://www.parliament.uk/about/how/laws/acts/

https://www.lexisnexis.co.uk/legal/guidance/good-practice-considerations-in-1 egislation-drafting

https://wslaw.co.uk/our-people/alison-gorlov/

https://assets.publishing.service.gov.uk/government/uploads/system/uploads/ attachment data/file/892409/OPC drafting guidance June 2020-1.pdf

https://www.parliament.uk/about/how/laws/acts/ 
https://www.legislation.gov.uk/ukpga/2020/16/introduction

https://harvardjol.com/2016/10/24/a-beginners-guide-to-legislative-drafting/

https://www.archives.gov/federal-register/write/legal-docs/clear-writing.html

[9] 2. The Scope and Application Domain of Cyborg Law: Regulation and Control: As Important as for Nuclear Energy

https://www.un.org/en/sections/issues-depth/atomic-energy/index.html

The UN and the nuclear age were born almost simultaneously. The horror of the Second World War, culminating in the nuclear blasts at Hiroshima and Nagasaki, brought home the need to address the nuclear issue. By its first resolution, the General Assembly established the UN Atomic Energy Commission to deal with the problems raised by the discovery of atomic energy. And a landmark address by United States President Dwight D. Eisenhower in 1953, "Atoms for Peace", led to the establishment in 1957 of the International Atomic Energy Agency (IAEA).

International Atomic Energy Agency

The International Atomic Energy Agency works with its Member States and multiple partners worldwide to promote the safe, secure and peaceful use of nuclear technologies. The IAEA's relationship with the United Nations is guided by an agreement signed in 1957. It stipulates that: "The Agency undertakes to conduct its activities in accordance with the Purposes and Principles of the United Nations Charter to promote peace and international co-operation, and in conformity with policies of the United Nations furthering the establishment of safeguarded worldwide disarmament and in conformity with any international agreements entered into pursuant to such policies." ...

https://www.nrc.gov/about-nrc/radiation/protects-you/reg-matls.html

Regulation of Radioactive Materials

Because of their potentially hazardous properties, the use of certain radioactive materials must be closely regulated to protect the health and safety of the public and the environment. Toward that end, the responsibility for licensing and regulating the use and handling of these materials is shared by the following governmental organizations:

The U.S. Environmental Protection Agency (EPA)

The Food and Drug Administration (FDA)

The U.S. Nuclear Regulatory Commission (NRC)

State Governments ...

https://www.world-nuclear.org/our-association/who-we-are/mission.aspx

Our Mission World Nuclear Association is the international organization that represents the global nuclear industry. Its mission is to promote a wider understanding of nuclear energy among key international influencers by producing authoritative information, developing common industry positions, and contributing to the energy debate. 
Membership of the World Nuclear Association encompasses: • Virtually all of the world's uranium mining, conversion, enrichment and fuel fabrication companies. All major reactor vendors. Nuclear utilities providing $70 \%$ of world nuclear generation. Major nuclear engineering, construction, and waste management companies; and research and development organisations. $\bullet$ Companies providing international services in nuclear transport, law, insurance, brokerage, industry analysis and finance. World Nuclear Association is the only industry organisation with a global mandate to promote nuclear energy. It is in a unique position to share and advance best practice and common messages globally, working alongside partner organisations: the IAEA, the inter-governmental body for technical and scientific cooperation in nuclear energy; WANO, the industry's reactor safety organisation; and other regional and national nuclear associations around the world.

All of our activities revolve around three strategic areas: 1: Nuclear Industry Cooperation

.. 2: Nuclear Information Management ... 3: Nuclear Energy Communication ...

https://www.world-nuclear.org/information-library/safety-and-security/safety -of-plants/appendices/nuclear-regulation-regulators.aspx

Nuclear Regulation \& Regulators: list of national authorities in 30 different countries.

https://hackernoon.com/thinking-in-the-age-of-cyborgs-7f1e3dcf3bb 9

Thinking in the age of cyborgs by Junaid Mubeen April 2 nd 2017

An educator's warning to Elon Musk

We have our clearest indication yet that the cyborgs are coming. Elon Musk has formally accepted his invitation to the AI party the only way he knows how: by founding a company. Neuralink will create brain-enhancing digital implants; the first step on the road to merging humans with software. Musk has taken on the mantel of preserving the human race, and he believes the only way to counter the threat of APs rapid ascent is by meshing together biological and digital forms of intelligence.

To date, cyborgs have been the preserve of Sci-Fi. But Musk has form for bringing outlandish fantasies to bear. In fact, to Musk the cyborg is no fantasy at all. He recently argued that humans have already merged with technology. Musk is not the first to make the point. over half a century has passed since Marshall McLuhan declared technology "the extensions of man". Who could doubt it? Not even the Amish, apparently... The promise of cyborgs is that the combined force of human and digital intelligence will be greater than the sum of its parts. Our record with technology snipes away at this optimistic outlook. Digital intelligence that is predicated on information processing undermines our innate, human intelligence. Perhaps the most empowering role of technology is in connecting humans to our own, collective intelligence. Something for Elon and oth- 
ers to think about as they plot their path to cognitive enhancement. Let's just hope they don't Google the answer.

I am a research mathematician turned educator working at the nexus of mathematics, education and innovation.

https://library.ric.edu/c.php?g=999089\&p=7233026

FYS 100: From Cy Young to Cyborg: Mathematics in Sports and Gaming

\section{[10] 3. Scientific Interface: FACLs as a Smart Contract}

https://www.globallegalinsights.com/practice-areas/blockchain-laws-and-regu lations

Blockchain Laws and Regulations Published: 23/10/2020 Joe Dewey, Holland \& Knight LLP

https://journals.sagepub.com/doi/abs/10.1177/0268396220924669

Is code law? Current legal and technical adoption issues and remedies for blockchain-enabled smart contracts Daniel Drummer, Dirk Neumann Journal of Information Technology First Published August 5, 2020

https://doi.org/10.1177/0268396220924669

Abstract Blockchain technology has enabled so-called smart contracts between different parties on a decentralized network. These self-enforceable and self-executable computerized contracts could initiate a fundamental paradigm shift in the understanding and functioning of our legal practices. Opportunities for their application are increasingly understood, and numerous tests of feasibility have been completed. However, only very few use cases have yet been implemented at scale. This article-as the first of its kind-comprehensively analyzes the underlying challenges and locates a key reason for the slow adoption in the discrepancy between legal requirements and IT capabilities. Our work combines a wide range of academic sources and interviews with 30 domain experts from IT, the legal domain and private industry ...

https://www.osborneclarke.com/insights/cryptoassets-smart-contracts-legal-st atus-english-law/

Cryptoassets and smart contracts / What is their legal status under English law? Written on 13 Dec 2019

Innovators and investors in blockchain-based business models can take comfort from a recent analysis that cryptoassets can be a form of legal property under English law and smart contracts are capable of forming enforceable contracts ...

https://www.lawcom.gov.uk/project/smart-contracts/

Smart contracts The issue Emerging technologies such as block chain are being promoted as a way to create "smart contracts". These are contracts that are performed automatically by computer code, without the need for human inter- 
vention. Smart contracts may take the form of a natural language contract which is executed using code, a hybrid contract consisting of natural language and coded terms or a contract which is written wholly in code. Smart contracts are expected to increase efficiency, trust and certainty in business....Following the publication of the Legal Statement in November 2019, the Government asked the Law Commission to undertake a scoping study into the law on smart contracts.

Terms of reference The Law Commission has agreed terms of reference with the Government for the scoping study. Briefly, the scoping study will:

- Analyse the current law as it applies to smart contracts, drawing on the conclusions of the Legal Statement. The analysis of the law will highlight any uncertainties or gaps, particularly in relation to:

o formation and enforceability

o Interpretation

0 performance of the contract

o remedies

o vitiating factors.

- Identify areas in which further work or reform may be required, and provide such advice as the Law Commission considers appropriate on options for reform.

Next steps The Commission began its work in August 2020, and in due course will publish a call for evidence. To contact us, or to be added to our mailing list and receive updates about this project, please email smart-contracts@lawcommission.gov.uk.

[11] 4. Principal Requirements and the Fundamental Articles of Cyborg Law-c) Proposition: No Exclusive or Universal Automation of Justice

Computer Bluff, Dr Stephen Castell, Quartermaine House, 1983, ISBN 0 $90589815 \mathrm{X}$, "The Which Computer book for people who know nothing about computers ... and would like to have left it that way". Once a best-seller, now out of print, it is still potentially available in 'good public libraries', and online: https://www.amazon.co.uk/Computer-Bluff-Stephen-Castell/dp/090589815X

'BERTIE, the First Electronic Barrister', Dr Stephen Castell, John Scannell and Sheila Richardson, Law Society's Gazette, Wednesday 21 May 1980.

https://www.lawgazette.co.uk/ ... publication of record to solicitors in England and Wales since 1903 ...

See also the "follow-up story" article: "HACKING OUT COMPUTER LEGISLATION" by Stephen Castell.UPDATE Magazine, Vol2No1, 1989, pp. 10-13.

https://www.law.com/legaltechnews/2020/01/29/ai-in-the-courts-the-good-th e-concerning-and-the-frightening/

AI in the Courts. The Good, the Concerning and the Frightening By Rhys 
Dipshan / January 29, 2020.

A panel at the New York State Bar Association's Annual Meeting looked at the ways AI can benefit, complicate and stifle the way judges and their courtrooms work. Artificial intelligence won't mean the end of the legal industry (or world) as we know it. But neither will it create utopia where new heights of insight and efficiency close the access to justice gap and take much of the guesswork out of the legal profession. The reality of Als future, and present, is far more ambiguous and complicated than that ...

https://www.law.com/legaltechnews/2020/01/23/what-the-future-holds-for-te chnology-in-the-courtroom/

What the Future Holds for Technology in the Courtroom

By Leon Hilliard “Hip' Hughes, Morrison \& Hughes / January 23, 2020

Cutting-edge breakthroughs in technology are changing the way lawyers argue cases and offering new ways for a case to carry real impact, in addition to making lawyers' lives a little easier.

http://arbitrationblog.kluwerarbitration.com/2019/12/16/can-a-robojudge-befair/

Can a robojudge be fair? Zbyněk Loebl(PRK Partners)/December 16, 2019

\section{Introduction}

At the latest ODR Forum which was held on 29-31 October 2019 in Williamsburg, Virginia, Dr Anyu Lee presented on China's vision of online dispute resolution (“ODR"). He discussed how far China has progressed in developing artificial intelligence (" $A P$ ”) tools for online courts, arbitration and mediation. He also described the potential of AI in resolving disputes and in particular mentioned that, cross-border small value dissatisfactions which are difficult to resolve at present could be resolved smoothly and efficiently in the near future through AI. Dr Lee concluded his presentation by arguing that the only way forward is to have these small value cross-border cases decided by robojudges/roboarbitrators/robomediators, and have their resolutions enforced by a social credit system. According to Dr Lee, in the near future, the first advanced robots will be able to speak multiple languages, know laws of different jurisdictions and analyze a large volume of court decisions, which will enable them to render correct and consistent decisions. Further, it was raised that judges, arbitrators and mediators should start training their own robots in order to compete with other robots in the near future.

\section{A robojudge cannot be fair}

While I agree with most of what Dr Lee presented, I disagree with his conclusions. Why? It is because our concept of fair justice is inseparable from human ethics...

https://www.ethicsforge.cc/robojudge-is-the-devil-in-the-data

RoboJudge: Is the Devil in the Data? 22nd March 2019 
The use of Artificial Intelligence $(A I)$ is becoming more common in a variety of industries, the legal profession being no exception. This article examines the ethics of using an AI as a judge to determine the sentencing in court cases. Judges use sentencing guidelines that are laid out by the Sentencing Council in order to provide a greater consistency in sentencing among judges. An AI system recently correctly predicted the outcome of hundreds of Human Rights cases with an accuracy of $79 \%$, demonstrating improvements are still needed. This article makes the ethical arguments based on certain assumed capabilities of an $A I$ judge:

- It is assumed that the AI system will be unbiased.

- The code for the AI itself will be written and owned by the judicial system and not outsourced from a 3 rd party.

- The algorithm will not be "black boxed" and will be open to interrogation.

- Humans will continue to deliver the verdict, with AI solely used to determine the sentencing ...

https://www.taylorwessing.com/fr/insights-and-events/insights/2018/10/roboj udges-the-future-or-fiction

Robojudges: the future or fiction? 16 October 2018

As part of our collaboration with 4 Pump Court, the leading technology chambers, we'll be publishing a series of articles over the next few months looking at the impact of technology on disputes. In the first article, Barrister Rebecca Keating looks at the role of "robojudges".

The future role of artificial intelligence $(A I)$ does not always get the best press. Titles such as "Superintelligence: Paths, Dangers, Strategies", "The Black Box Society" and "Weapons of Math Destruction" can leave one feeling that the future of AI is a dangerous path filled with peril-our day to day utility destined for replacement by a smarter, more efficient and secretive robot. However, the ever-increasing role of $A I$ is fast becoming a certainty. The government announced just this month, in a press release creatively entitled" [p]rojects lay the groundwork for a future of robolawyers and flying cars", that the Solicitors Regulation Authority (SRA) will award nearly $£ 700,000$ to fund AI projects to transform the legal services market for small businesses and consumers. [1] This is but one of the many attempts to increasingly use AI projects in the legal sphere to assist lawyers. However, going one step further, this article explores the role of not just the robolawyer but the robojudge. While AI tools for robolawyers are tools to assist, the role of the robojudge is quite different. These tools either assist in determining the dispute, actually determine an element of the dispute or indeed determine the entirety of the dispute. Algorithms are structured decision-making processes. A set of rules is decided upon to deliver results according to those set rules. These predetermined parameters define the limits and elements of the decision. Further if machine learning is utilised, the AI system may learn by considering both previous decisions and new data, thus refining its processes to improve its decision making for future decisions. When put 
like that one can see the appeal in AI in the judicial sphere. It reflects in many ways how we believe current decisions are made and indeed should be made learning from previous decisions and taking into account new information ...

https://www.standard.co.uk/news/crime/robots-will-replace-lawyers-in-courtsays-head-of-serious-fraud-office-a3694646.html

"Robots will replace lawyers in court" says head of Serious Fraud Office MARTIN BENTHAM November 18, 2017

Artificial intelligence will soon be used routinely instead of lawyers to prepare criminal cases, one of Britain's top prosecutors said today. David Green, director of the Serious Fraud Office, ... said ... "In a few years' time I can imagine the courts expressing themselves in favour of wider use of this kind of artificial intelligence," ... "It's done fairly routinely in civil cases, but if you imagine it being applied to finding things of relevance in a criminal investigation you could get through very large amounts of information." Mr Green said AI could also be used in relation to disclosure, where prosecutors are obliged to make certain material available to the defence: "It would require defence consent or permission from the court, but I can imagine that not being far away. Why not? ..." ...

https://cacm.acm.org/news/221340-robot-judges-edmonton-research-crafting -artificial-intelligence-for-courts/fulltext

Robot Judges? Edmonton Research Crafting Artificial Intelligence for Courts

By CBC News (Canada) September 25, 2017

University of Alberta professor Randy Goebels team in Canada is working with researchers in Japan to develop artificial intelligence software for legal reasoning, after they successfully created an algorithm that can pass the Japanese bar exam. Goebel says the software is being designed to weigh contradicting legal evidence, rule on cases, and forecast the outcomes of future trials...

http://blogs.discovermagazine.com/crux/2017/05/16/are-we-ready-for-robot-j udges/\#.WrtuRojwY2w

Are We Ready for Robot Judges? By Christopher Markou, University of Cambridge / May 16, 2017

Artificial intelligence is already helping determine your future ... But can we agree, at least for now, that having an AI determine your guilt or innocence in a court of law is a step too far? Worryingly, it seems this may already be happening. When American Chief Justice John Roberts recently attended an event, he was asked whether he could foresee a day "when smart machines, driven with artificial intelligences, will assist with courtroom fact finding or, more controversially even, judicial decision making". He responded: "It's a day that's here and it s putting a significant strain on how the judiciary goes about doing things". ... What sort of cognitive biases are involved when an all-powerful "smart" system like Compas suggests what a judge should do? ...

http://www.artificialintelligenceinsight.org/category/robojudges 
Category: RoboJudgesby DFI 14. December 2016

An AI study convinced the world that robo-judges can predict the outcome of litigation only it was wrong

Will robo-judges replace human judges? About a month ago, an incredible story that machine learning could predict the outcome of Court decisions with $79 \%$ accuracy made international headlines. The story was newsworthy because of its obvious implications, namely that a $\$ 500$ computer could, with some coding, replace human judges and produce judgements as accurate as humans ...

https://www.independent.co.uk/life-style/gadgets-and-tech/news/ai-judge-rob ot-european-court-of-human-rights-law-verdicts-artificial-intelligence-a737735 $\underline{1 . h t m l}$

ANDREW GRIFFIN Monday 24 October 2016

An artificial intelligence $(A I)$ judge has accurately predicted most verdicts of the European Court of Human Rights, and might soon be making important decisions about cases. Scientists built an artificial intelligence computer that was able to look at legal evidence as well as considering ethical questions to decide how a case should be decided. And it predicted those with 79 per cent accuracy, according to its creators. The algorithm looked at data sets made up 584 cases relating to torture and degrading treatment, fair trials and privacy. The computer was able to look through that information and make its own decision which lined up with those made by Europe's most senior judges in almost every case....

https://www.ncsc.org/topics/technology/technology-in-the-courts/resource-g uide

Technology in the Courts Resource Guide

"Technology is a powerful enabler that can empower courts to meet core purposes and responsibilities, even while severe economic pressures reduce court staff, reduce hours of operation, and even close court locations. To harness technology for this purpose, serious efforts are needed to examine process, re-engineering opportunities, and courts must plan to (a) migrate from document to content management and (b) initiate customer relations management to improve the quality of justice, access to justice, and public trust and confidence in courts as an institution."-Chris Crawford

[12] 5. Developing Further Cyborg Law: Towards Government by Algorithm? -UK's A-Level Grade-Assigning Algorithm from Ofqual

https://www.bcs.org/more/about-us/press-office/press-releases/algorithms-m ust-meet-ethical-and-professional-standards-to-recover-public-trust-report-reco $\underline{\text { mmends/ }}$

BCS Policy Team report "The Exam Question: How do we make algorithms do the right thing?"

Algorithms must meet ethical and professional standards to recover public 
trust ... 1 September 2020

Algorithms that change people's lives-for example when estimating students grades-should now meet strict standards of ethics and competence, according to a new report by the professional body for IT ...

\section{Biographical Note}

Dr Stephen Castell CITP CPhys FIMA MEWI MIoD, Medallist, IT CONSULTANT OF THE YEAR (BCS Professional Awards), is an internationally acknowledged independent ICT expert, management consultant and project manager professional, with extensive experience in risk assessment, quality assurance, and insurance and dispute resolution considerations, in regard to complex and large-scale ICT systems, technology, investment, contracts, implementation projects and operations. For over thirty years Dr Castell has acted internationally as an expert witness in major complex computer software and systems disputes and litigation, including the largest and longest such actions to have reached the English High Court (AirTours v EDS,2001; GEC-Marconi v LFCDA, 1992), and Sydney Supreme Court (ITSL \& ERG V PTTC, 2012), and in IP (patent, software copyright, commercial secrets actions, e.g. USA cases BI vEchostar and Lodsys $v$ Kaspersky), data forensics, e-document authentication, software and technology valuation and quantum, and blockchain and cryptocurrency forensics cases. His seminal paper "Forensic Systems Analysis: A Methodology for Assessment and Avoidance of IT Disasters and Disputes" is a Cutter Consortium Executive Report, Enterprise Risk Management \& Governance Advisory Service series (Vol. 3, No. 2, March 8, 2006).

Dr Castell has also established a reputation in the building of multimillion pound businesses in voice and data communications, and in broadcasting, information, media and software services, having acted as Business Development Consultant for and on behalf of both the BBC and BT. In the early 1980s he was a pioneer of the Over The Counter Market in the UK, responsible for assessing several hundred high-tech and telecommunications companies in a 5-year period, in preparing their flotation prospectuses, and serving as Non-Executive Director. In 1982, he was founder Technical Director of the venture capital funded International Communications Technology Holdings $S A$, based in Luxembourg and listed in London, and was Chairman of its UK subsidiary Telephone Broadcasting Systems plc.

Dr Castell has for over forty years been a thought-leader and business entrepreneur in the field of ICT and the Law. With Neil Maybury, solicitor, in 1977 he notably co-founded Infolex, the UK's first computer-assisted legal information retrieval system for practising lawyers, and successfully marketed subscriptions to its unique CLARUS Case Law Report Updating Service to legal profession practitioners, both nationally and internationally. Infolex was sold in 1984 to Wolters Sampson the major Dutch publishing corporation. In the APPEAL Report (Dr Stephen Castell, 1990, Eclipse Publications, ISBN 1-870771-03-6), 
still regarded by many in the field as definitive, and based on de-classified research carried out for H M Treasury on behalf of the five major Departments of State of the UK Government, he exhaustively studied and reported on the legal reliability and security of IT software, systems and media, and formulated the still fundamental insight: Castell s First Dictum: "You cannot secure an ontologically unreliable technology by use of an ontologically unreliable technology". Dr Castell has been honoured with an interview for Archives of IT: https://archivesit.org.uk/

Archives of IT Capturing the Past, Inspiring the Future

In-depth experiences of the people who influenced the development of IT in the $U K$

https://archivesit.org.uk/interviews/stephen-castell/ 